\title{
Common fixed points for self-mappings on partial metric spaces
}

\author{
Cristina Di Bari ${ }^{1}$, Marija Milojević2 ${ }^{2}$ Stojan Radenović ${ }^{3 *}$ and Pasquale Vetro'
}

\author{
"Correspondence: \\ radens@beotel.net \\ ${ }^{3}$ Faculty of Mechanical Engineering, \\ University of Belgrade, Kraljice \\ Marije 16, Beograd, 11120, Serbia \\ Full list of author information is \\ available at the end of the article
}

\begin{abstract}
In this paper, we prove some results of a common fixed point for two self-mappings on partial metric spaces. Our results generalize some interesting results of llić et al. (Appl. Math. Lett. 24:1326-1330, 2011). We conclude with a result of the existence of a fixed point for set-valued mappings in the context of 0-complete partial metric spaces.
\end{abstract}

MSC: $54 \mathrm{H} 25 ; 47 \mathrm{H} 10$

Keywords: points of coincidence; common fixed points; 0-complete partial metric space; $\psi$-contractions

\section{Introduction}

In the mathematical field of domain theory, attempts were made to equip semantics domain with a notion of distance. In particular, Matthews [1] introduced the notion of a partial metric space as a part of the study of denotational semantics of data for networks, showing that the contraction mapping principle can be generalized to the partial metric context for applications in program verification. Moreover, the existence of several connections between partial metrics and topological aspects of domain theory have been lately pointed out by other authors such as O'Neill [2], Bukatin and Scott [3], Bukatin and Shorina [4], Romaguera and Schellekens [5] and others.

After the definition of the concept of a partial metric space, Matthews [1] obtained a Banach type fixed point theorem on complete partial metric spaces. This result was recently generalized by Ilić et al. [6]. In this paper, we prove some results of a common fixed point for two self-mappings on partial metric spaces. Our results generalize some interesting results of Ilić et al. We conclude this paper with a new existence result of a fixed point for set-valued mappings in a partial metric space.

\section{Preliminaries}

First, we recall some definitions and some properties of partial metric spaces that can be found in [2,5-27]. A partial metric on a nonempty set $X$ is a function $p: X \times X \rightarrow[0,+\infty[$ such that for all $x, y, z \in X$,

$\left(p_{1}\right) x=y \Leftrightarrow p(x, x)=p(x, y)=p(y, y)$,

$\left(p_{2}\right) p(x, x) \leq p(x, y)$,

(p $\left.p_{3}\right) p(x, y)=p(y, x)$,

$\left(p_{4}\right) \quad p(x, y) \leq p(x, z)+p(z, y)-p(z, z)$. 
It is clear that $\left(p_{4}\right)$ implies the triangular inequality. A partial metric space is a pair $(X, p)$ such that $X$ is a nonempty set and $p$ is a partial metric on $X$. It is clear that if $p(x, y)=0$, then from $\left(p_{1}\right)$ and $\left(p_{2}\right)$, it follows that $x=y$. But if $x=y, p(x, y)$ may not be 0 . A basic example of a partial metric space is the pair $([0,+\infty[, p)$, where $p(x, y)=\max \{x, y\}$ for all $x, y \in[0,+\infty[$. Other examples of partial metric spaces, which are interesting from a computational point of view, can be found in [1].

Each partial metric $p$ on $X$ generates a $T_{0}$ topology $\tau_{p}$ on $X$ which has as a base the family of open $p$-balls $\left\{B_{p}(x, \varepsilon): x \in X, \varepsilon>0\right\}$, where

$$
B_{p}(x, \varepsilon)=\{y \in X: p(x, y)<p(x, x)+\varepsilon\}
$$

for all $x \in X$ and $\varepsilon>0$.

If $p$ is a partial metric on $X$, then the function $p^{s}: X \times X \rightarrow[0,+\infty[$ given by

$$
p^{s}(x, y)=2 p(x, y)-p(x, x)-p(y, y)
$$

is a metric on $X$.

Definition 1 Let $(X, p)$ be a partial metric space.

(i) A sequence $\left\{x_{n}\right\}$ in $(X, p)$ converges to a point $x \in X$ if and only if $p(x, x)=\lim _{n \rightarrow+\infty} p\left(x, x_{n}\right)$.

(ii) A sequence $\left\{x_{n}\right\}$ in $(X, p)$ is called a Cauchy sequence if there exists (and is finite) $\lim _{n, m \rightarrow+\infty} p\left(x_{n}, x_{m}\right)$.

(iii) A partial metric space $(X, p)$ is said to be complete if every Cauchy sequence $\left\{x_{n}\right\}$ in $X$ converges, with respect to $\tau_{p}$, to a point $x \in X$ such that $p(x, x)=\lim _{n, m \rightarrow+\infty} p\left(x_{n}, x_{m}\right)$.

(iv) A sequence $\left\{x_{n}\right\}$ in $(X, p)$ is called 0-Cauchy if $\lim _{n, m \rightarrow+\infty} p\left(x_{n}, x_{m}\right)=0$.

We say that $(X, p)$ is 0 -complete if every 0 -Cauchy sequence in $X$ converges, with respect to $\tau_{p}$, to a point $x \in X$ such that $p(x, x)=0$.

On the other hand, the partial metric space $(\mathbb{Q} \cap[0,+\infty[, p)$, where $\mathbb{Q}$ denotes the set of rational numbers and the partial metric $p$ is given by $p(x, y)=\max \{x, y\}$, provides an example of a 0 -complete partial metric space which is not complete.

It is easy to see that every closed subset of a complete partial metric space is complete.

Lemma 1 ([9]) Let $(X, p)$ be a partial metric space and $\left\{x_{n}\right\} \subset X$. If $x_{n} \rightarrow x \in X$ and $p(x, x)=0$, then $\lim _{n \rightarrow+\infty} p\left(x_{n}, z\right)=p(x, z)$ for all $z \in X$.

Define $p(x, A)=\inf \{p(x, a): a \in A\}$. Then $a \in \bar{A} \Leftrightarrow p(a, A)=p(a, a)$, where $\bar{A}$ denotes the closure of $A$ (for details see [10], Lemma 1 ).

Let $X$ be a non-empty set and $T, f: X \rightarrow X$. The mappings $T, f$ are said to be weakly compatible if they commute at their coincidence point (i.e., $T f x=f T x$ whenever $T x=f x$ ). A point $y \in X$ is called a point of coincidence of $T$ and $f$ if there exists a point $x \in X$ such that $y=T x=f x$.

Lemma 2 (Proposition 1.4 of [28]) Let $X$ be a non-empty set and the mappings $T$, $f: X \rightarrow$ $X$ have a unique point of coincidence $v$ in $X$. If $T$ and $f$ are weakly compatible, then $v$ is a unique common fixed point of $T$ and $f$. 


\section{Main results}

Let $(X, p)$ be a partial metric space and $T, f: X \rightarrow X$ be such that $T X \subset f X$. For every $x_{0} \in X$, we consider a sequence $\left\{x_{n}\right\} \subset X$ defined by $f x_{n}=T x_{n-1}$ for all $n \in \mathbb{N}$ and we say that $\left\{T x_{n}\right\}$ is a $T-f$-sequence of the initial point $x_{0}$ (see [29]). Set

$$
\rho_{f}:=\inf \{p(f x, f x): x \in X\} \quad \text { and } \quad X_{f}=\left\{x \in X: p(f x, f x)=\rho_{f}\right\} .
$$

It is not always $X_{f} \neq \emptyset$. This is true if and only if $\rho_{f}=\min \{p(f x, f x): x \in X\}$. If $X=[0,+\infty[$, $p(x, y)=\max \{x, y\}, f x=x, x \neq 0$ and $f 0>0$, then $\rho_{f}=0$ and $X_{f}=\emptyset$.

Let $(X, p)$ be a partial metric space. We denote with $\mathcal{F}$ the family of pairs $(T, f)$ such that:

(i) $T$ and $f$ are self-mappings on $X$ with $T X \subset f X$;

(ii) for each $x, y \in X$ the following condition holds:

$$
p(T x, T y) \leq \max \{k p(f x, f y), p(f x, f x), p(f y, f y)\}
$$

where $k \in[0,1[$.

Remark 1 If $(T, f) \in \mathcal{F}$, then for each $x \in X$, we have

$$
\rho_{f} \leq p(T x, T x) \leq p(f x, f x) .
$$

Indeed, because $T X \subset f X$, we have that $\{p(T x, T x): x \in X\}=B \subset A=\{p(f x, f x): x \in X\}$ from which follows $\inf A \leq \inf B$, that is, $\rho_{f} \leq \rho_{T} \leq p(T x, T x) \leq p(f x, f x)$.

Lemma 3 Let $(X, p)$ be a partial metric space with $(T, f) \in \mathcal{F}$ and $X_{f} \neq \emptyset$. If $u, v \in X_{f}$ are coincidence points for $T$ and $f$, then $f u=f v$.

Proof From

$$
p(f u, f v)=p(T u, T v) \leq \max \{k p(f u, f v), p(f u, f u), p(f v, f v)\}
$$

it follows that either $(1-k) p(f u, f v)=0$ or $p(f u, f v) \leq p(f u, f u)=p(f v, f v)=\rho_{f}$. Now, from $\left(p_{2}\right)$, it follows $p(f u, f v)=\rho_{f}=\min \{p(f x, f x): x \in X\}$, that is, $f u=f v$.

Lemma 4 Let $(X, p)$ be a partial metric space and $(T, f) \in \mathcal{F}$. If $X$ is a complete subspace of $X$, then for each $s \in \mathbb{N}$, there is $x \in X$ such that

$$
p(f x, f x)=p(f x, T x)<\rho_{f}+\frac{1}{s} .
$$

Proof We fix $x_{0} \in X$ and prove that each $T-f$-sequence $\left\{T x_{n}\right\}$ of the initial point $x_{0}$ is a Cauchy sequence in $T X$.

From Remark 1, we deduce that $p\left(T x_{n+1}, T x_{n+1}\right) \leq p\left(f x_{n+1}, f x_{n+1}\right)=p\left(T x_{n}, T x_{n}\right)$. Hence, $\left\{p\left(T x_{n}, T x_{n}\right)\right\}$ is a nonincreasing sequence. Set

$$
r:=\inf \left\{p\left(T x_{n}, T x_{n}\right)\right\}=\lim _{n \rightarrow+\infty} p\left(T x_{n}, T x_{n}\right) \leq p\left(f x_{0}, f x_{0}\right)
$$


and

$$
M:=\frac{1}{1-k} p\left(f x_{0}, T x_{0}\right)+p\left(f x_{0}, f x_{0}\right)
$$

We prove that

$$
p\left(f x_{0}, T x_{n}\right) \leq M, \quad \text { for all } n \in \mathbb{N} .
$$

Obviously, (3.2) is true for $n=0,1$. Assume that (3.2) is true for some $n \geq 1$, then

$$
\begin{aligned}
p\left(f x_{0}, T x_{n+1}\right) & \leq p\left(f x_{0}, T x_{0}\right)+p\left(T x_{0}, T x_{n+1}\right) \\
& \leq p\left(f x_{0}, T x_{0}\right)+\max \left\{k p\left(f x_{0}, T x_{n}\right), p\left(f x_{0}, f x_{0}\right)\right\} \\
& \leq p\left(f x_{0}, T x_{0}\right)+\frac{k}{1-k} p\left(f x_{0}, T x_{0}\right)+p\left(f x_{0}, f x_{0}\right) \\
& =M .
\end{aligned}
$$

We fix $\varepsilon>0$ and choose $n_{0} \in \mathbb{N}$ such that $p\left(T x_{n}, T x_{n}\right)<r+\varepsilon$ for all $n \geq n_{0}$ and $2 k^{n_{0}} M<$ $r+\varepsilon$. For each $m \geq n \geq 2 n_{0}$, we have

$$
\begin{aligned}
p\left(T x_{n}, T x_{m}\right) \leq & \max \left\{k p\left(T x_{n-1}, T x_{m-1}\right), p\left(T x_{n-1}, T x_{n-1}\right)\right\} \\
\leq & \max \left\{k^{2} p\left(T x_{n-2}, T x_{m-2}\right), p\left(T x_{n-2}, T x_{n-2}\right)\right\} \\
& \cdots \\
\leq & \max \left\{k^{n_{0}} p\left(T x_{n-n_{0}}, T x_{m-n_{0}}\right), p\left(T x_{n-n_{0}}, T x_{n-n_{0}}\right)\right\} \\
\leq & \max \left\{k^{n_{0}}\left[p\left(T x_{n-n_{0}}, f x_{0}\right)+p\left(f x_{0}, T x_{m-n_{0}}\right)\right],\right. \\
& \left.p\left(T x_{n-n_{0}}, T x_{n-n_{0}}\right)\right\} \\
< & r+\varepsilon .
\end{aligned}
$$

Now, from

$$
r \leq p\left(T x_{n}, T x_{n}\right) \leq p\left(T x_{n}, T x_{m}\right)<r+\varepsilon
$$

for each $m \geq n \geq 2 n_{0}$, we obtain that

$$
\lim _{n, m \rightarrow+\infty} p\left(T x_{n}, T x_{m}\right)=r=\lim _{n, m \rightarrow+\infty} p\left(f x_{n}, f x_{m}\right) .
$$

Since $f X$ is a complete subspace of $X$, there is $z \in f X$ such that

$$
p(z, z)=\lim _{n \rightarrow+\infty} p\left(z, T x_{n}\right)=\lim _{n, m \rightarrow+\infty} p\left(T x_{n}, T x_{m}\right)=r .
$$

Let $x \in X$ such that $f x=z$. We show that $p(f x, f x)=p(f x, T x)=r$.

Now, from (3.1), we deduce that there exist $I_{1}, I_{2}, I_{3} \subset \mathbb{N}$ such that

(i) $p\left(T x_{n}, T x\right) \leq k p\left(f x_{n}, f x\right)$ for all $n \in I_{1}$;

(ii) $p\left(T x_{n}, T x\right) \leq p\left(f x_{n}, f x_{n}\right)$ for all $n \in I_{2}$; 
(iii) $p\left(T x_{n}, T x\right) \leq p(f x, f x)$ for all $n \in I_{3}$.

Clearly, at least one of the sets $I_{1}, I_{2}, I_{3}$ is infinite.

Then, from

$$
p(f x, T x) \leq p\left(f x, T x_{n}\right)+p\left(T x_{n}, T x\right)-p\left(T x_{n}, T x_{n}\right)
$$

if $I_{i}(i=1,2,3)$ is infinite, taking the limit as $n \rightarrow+\infty$ and $n \in I_{i}$, it follows that $p(f x, T x) \leq$ $p(f x, f x)$ and so $p(f x, T x)=p(f x, f x)$.

Now, if we choose $x_{0} \in X$ such that $p\left(f x_{0}, f x_{0}\right)<\rho_{f}+1 / s$, we deduce that $p(f x, f x) \leq$ $p\left(f x_{0}, f x_{0}\right)<\rho_{f}+1 / s$. If $x_{0} \in X_{f}$, also $x \in X_{f}$.

Lemma 5 Let $(X, p)$ be a partial metric space and $(T, f) \in \mathcal{F}$. If $f X$ is a complete subspace of $X$, then there exists $u \in X_{f}$ such that $f u=T u$.

Proof By Lemma 4, there exists a sequence $\left\{x_{n}\right\} \subset X$ such that

$$
p\left(f x_{n}, f x_{n}\right)=p\left(f x_{n}, T x_{n}\right)<\rho_{f}+\frac{1}{n}
$$

for all $n \in \mathbb{N}$. First, we prove that

$$
\lim _{n, m \rightarrow+\infty} p\left(f x_{n}, f x_{m}\right)=\rho_{f}
$$

For $\varepsilon>0$ fixed, we choose $n>3 / \varepsilon(1-k)$. From Remark 1 , it follows

$$
\rho_{f} \leq p\left(T x_{n}, T x_{n}\right) \leq p\left(f x_{n}, f x_{n}\right)=p\left(f x_{n}, T x_{n}\right)<\rho_{f}+\frac{1}{n}<\rho_{f}+\frac{\varepsilon}{3}(1-k),
$$

which implies

$$
p\left(f x_{n}, T x_{n}\right)-p\left(T x_{n}, T x_{n}\right)<\frac{\varepsilon}{3}(1-k) .
$$

Now, for all $n, m>3 / \varepsilon(1-k)$, we have

$$
\begin{aligned}
p\left(f x_{n}, f x_{m}\right) \leq & p\left(f x_{n}, T x_{n}\right)+p\left(T x_{n}, T x_{m}\right)+p\left(T x_{m}, f x_{m}\right) \\
& -p\left(T x_{n}, T x_{n}\right)-p\left(T x_{m}, T x_{m}\right) \\
= & p\left(f x_{n}, T x_{n}\right)-p\left(T x_{n}, T x_{n}\right)+p\left(T x_{m}, f x_{m}\right) \\
& -p\left(T x_{m}, T x_{m}\right)+p\left(T x_{n}, T x_{m}\right) \\
< & \frac{2}{3} \varepsilon(1-k)+\max \left\{k p\left(f x_{n}, f x_{m}\right), p\left(f x_{n}, f x_{n}\right), p\left(f x_{m}, f x_{m}\right)\right\} .
\end{aligned}
$$

If $\max \left\{k p\left(f x_{n}, f x_{m}\right), p\left(f x_{n}, f x_{n}\right), p\left(f x_{m}, f x_{m}\right)\right\}=k p\left(f x_{n}, f x_{m}\right)$, then

$$
p\left(f x_{n}, f x_{m}\right)<\frac{2}{3} \varepsilon(1-k)+k p\left(f x_{n}, f x_{m}\right)
$$

and so $p\left(f x_{n}, f x_{m}\right)<\frac{2}{3} \varepsilon$. This implies that $\rho_{f} \leq \lim _{n, m \rightarrow+\infty} p\left(f x_{n}, f x_{m}\right)=0$. 
If

$$
\begin{aligned}
& \max \left\{k p\left(f x_{n}, f x_{m}\right), p\left(f x_{n}, f x_{n}\right), p\left(f x_{m}, f x_{m}\right)\right\} \\
& =\max \left\{p\left(f x_{n}, f x_{n}\right), p\left(f x_{m}, f x_{m}\right)\right\}<\rho_{f}+\frac{1}{3} \varepsilon(1-k),
\end{aligned}
$$

then

$$
\rho_{f} \leq p\left(f x_{n}, f x_{m}\right)<\frac{2}{3} \varepsilon(1-k)+\rho_{f}+\frac{1}{3} \varepsilon(1-k) .
$$

This implies that

$$
\lim _{n, m \rightarrow+\infty} p\left(f x_{n}, f x_{m}\right)=\rho_{f}
$$

In both cases, (3.4) holds. Since $f X$ is a complete subspace of $X$, there is $z \in f X$ such that

$$
p(z, z)=\lim _{n \rightarrow+\infty} p\left(z, f x_{n}\right)=\lim _{n, m \rightarrow+\infty} p\left(f x_{n}, f x_{m}\right)=\rho_{f} .
$$

Let $u \in X$ such that $f u=z$. From $p(f u, f u)=p(z, z)$ it follows that $u \in X_{f}$. We prove that $p(f u, f u)=p(f u, T u)$. As $p\left(f x_{n}, f x_{n}\right)=p\left(f x_{n}, T x_{n}\right)$ and $\rho_{f} \leq p\left(T x_{n}, T x_{n}\right)$ for all $n \in \mathbb{N}$, we get that

$$
\begin{aligned}
p(f u, T u) \leq & p\left(f u, f x_{n}\right)+p\left(f x_{n}, T x_{n}\right)+p\left(T x_{n}, T u\right) \\
& -p\left(f x_{n}, f x_{n}\right)-p\left(T x_{n}, T x_{n}\right) \\
= & p\left(f u, f x_{n}\right)+p\left(T x_{n}, T u\right)-p\left(T x_{n}, T x_{n}\right) \\
\leq & p\left(f u, f x_{n}\right)-\rho_{f}+p\left(T x_{n}, T u\right) \\
\leq & p\left(f u, f x_{n}\right)-\rho_{f}+\max \left\{k p\left(f x_{n}, f u\right), p\left(f x_{n}, f x_{n}\right), p(f u, f u)\right\} .
\end{aligned}
$$

As $n \rightarrow+\infty$, we obtain $p(f u, T u)=p(f u, f u)=p(T u, T u)=\rho_{f}$ and so $f u=T u$.

The following theorem of a common fixed point in a partial metric space is one of our main results.

Theorem 1 Let $(X, p)$ be a partial metric space with $(T, f) \in \mathcal{F}$. IffX is a complete subspace of $X$, then $T$ and $f$ have a unique point of coincidence $z=f u=T u$ with $u \in X_{f}$. Moreover, if $T$ and $f$ are weakly compatible and $f X_{f} \subset X_{f}$, then $T$ and $f$ have a unique common fixed point $z \in X_{f}$.

Proof By Lemma 5 and Lemma 3, there exists $u \in X_{f}$ such that $z=f u=T u$ is a unique point of coincidence for $T$ and $f$ with $p(z, z)=\rho_{f}$. If $T$ and $f$ are weakly compatible and $f X_{f} \subset X_{f}$, by Lemma 3, from $T z=T f u=f T u=f z \in X_{f}$, that is $p(f z, f z)=\rho_{f}$, it follows that $f z=f u$. By Lemma 2, $z$ is a unique common fixed point for $T$ and $f$ belonging to $X_{f}$.

Theorem 2 Let $(X, p)$ be a partial metric space and $T, f: X \rightarrow X$. Suppose that the following condition holds:

$$
p(T x, T y) \leq \max \left\{k p(f x, f y), \frac{p(f x, f x)+p(f y, f y)}{2}\right\},
$$


for each $x, y \in X$, where $k \in[0,1$ [. If $X$ is a complete subspace of $X$, and $T$ and $f$ are weakly compatible, then $T$ and $f$ have a unique common fixed point $z \in X$.

Proof Clearly, $(T, f) \in \mathcal{F}$, by Lemma 5, there exists $u \in X_{f}$ such that $z=f u=T u$. If $v \in X$ is such that $f v=T v$ and $p(f v, f v)=p(f u, f u)$, then $f u=f v$ by Lemma 3. If $p(f v, f v)>p(f u, f u)$, from (3.5) we obtain either $p(f u, f v)=p(T u, T v) \leq k p(f u, f v)$ or $p(f u, f v)=p(T u, T v)<$ $p(f v, f v)$. In each of these cases, we deduce that $f u=f v$, and so $T$ and $f$ have a unique point of coincidence. By Lemma 2 , since $T$ and $f$ are weakly compatible, $T$ and $f$ have a unique common fixed point $z \in X$.

If in Theorems 1 and 2 we choose $f(x)=x$, we obtain Theorems 3.1 and 3.3 of Ilić $e t$ al.

Example 1 Let $X=[0,6]$ and $p: X \times X \rightarrow \mathbb{R}$ be defined by $p(x, y)=\max \{x, y\}$. Then $(X, p)$ is a complete partial metric space. Let $T, f: X \rightarrow X$ be defined by

$$
T x= \begin{cases}2 x-1 & \text { if } x \in[1,3], \\ 3 & \text { if } x \in] 3,6]\end{cases}
$$

and

$$
f x= \begin{cases}1 & \text { if } x=1, \\ 2 & \text { if } x \in] 1,4 / 3[ \\ 2 x & \text { if } x \in[4 / 3,3] \\ 6 & \text { if } x \in] 3,6]\end{cases}
$$

respectively.

In order to show that $T$ and $f$ satisfy the contractive condition (3.5) in Theorem 2 with $k=5 / 6$, we consider the following cases.

Case 1. $x=y=1$. We have

$$
\begin{aligned}
p(T 1, T 1) & =1=\frac{p(f 1, f 1)+p(f 1, f 1)}{2} \\
& =\max \left\{k p(f 1, f 1), \frac{p(f 1, f 1)+p(f 1, f 1)}{2}\right\} .
\end{aligned}
$$

Case 2. $x, y \in[1,4 / 3[$ and $x<y$. We have

$$
p(T x, T y)=2 y-1 \leq \frac{5}{6} 2 \leq \max \left\{k p(f x, f y), \frac{p(f x, f x)+p(f y, f y)}{2}\right\} .
$$

Case 3. $x \in[1,3], y \in[4 / 3,3]$ and $x<y$. We have

$$
p(T x, T y)=2 y-1 \leq \frac{5}{6} 2 y \leq \max \left\{k p(f x, f y), \frac{p(f x, f x)+p(f y, f y)}{2}\right\} .
$$

Case 4. $x \in[1,3]$ and $y \in] 3,6]$. We have

$$
p(T x, T y)=\max \{3,2 x-1\} \leq \frac{5}{6} 6 \leq \max \left\{k p(f x, f y), \frac{p(f x, f x)+p(f y, f y)}{2}\right\} .
$$


Case 5. $x, y \in] 3,6]$. We have

$$
p(T x, T y)=3 \leq \frac{5}{6} 6 \leq \max \left\{k p(f x, f y), \frac{p(f x, f x)+p(f y, f y)}{2}\right\} .
$$

Since $f X$ is a complete subspace of $X$, and $T$ and $f$ are weakly compatible, by Theorem 2 , $T$ and $f$ have a unique common fixed point $z=1$.

\section{Fixed points for set-valued mappings}

Investigations of the existence of fixed points of set-valued contractions in metric spaces were initiated by Nadler [30]. The following theorem is motivated by Nadler's results and also generalizes the well-known Banach contraction theorem in several ways.

Denote with $\Psi$ the family of nondecreasing functions $\psi:[0,+\infty[\rightarrow[0,+\infty[$ such that $\sum_{n=1}^{+\infty} \psi^{n}(t)<+\infty$ for each $t>0$, where $\psi^{n}$ is the $n$th iterate of $\psi$.

Lemma 6 For every function $\psi \in \Psi$, the following holds: $\psi(t)<t$ for each $t>0$.

Definition 2 Let $(X, p)$ be a partial metric space and let $T: X \rightarrow C(X)$, where $C(X)$ is the family of nonempty closed subsets of $X$. T is $\psi$-contractive if there exists $\psi \in \Psi$ such that, for any $x_{1}, x_{2} \in X$ and $y_{1} \in T x_{1}$, there is $y_{2} \in T x_{2}$ with

$$
p\left(y_{1}, y_{2}\right) \leq \psi\left(p\left(x_{1}, x_{2}\right)\right)
$$

Theorem 3 Let $(X, p)$ be a 0-complete partial metric space and let $T: X \rightarrow C(X)$ be a $\psi$ contractive mapping. Then there exists $z \in X$ such that $z \in T z$, i.e., $z$ is a fixed point of $T$, and $p(z, z)=0$.

Proof Fix $x_{0} \in \mathrm{X}$ and let $x_{1} \in T x_{0}$. If $p\left(x_{0}, x_{1}\right)=0$, then $x_{1}=x_{0}$ and $x_{0}$ is a fixed point of $T$. Assume, hence, $p\left(x_{0}, x_{1}\right)>0$; then there exists $x_{2} \in T x_{1}$ such that $p\left(x_{1}, x_{2}\right) \leq \psi\left(p\left(x_{0}, x_{1}\right)\right)$. Proceeding in this way, we have a sequence $\left\{x_{n}\right\}$ in $X$ such that $x_{n+1} \in T x_{n}$ and $p\left(x_{n}, x_{n+1}\right) \leq$ $\psi\left(p\left(x_{n-1}, x_{n}\right)\right)$ for every $n \in \mathbb{N}$. Consequently,

$$
p\left(x_{n}, x_{n+1}\right) \leq \psi^{n}\left(p\left(x_{0}, x_{1}\right)\right), \quad \text { for all } n \in \mathbb{N} \text {. }
$$

Since, the series $\sum_{n=1}^{+\infty} \psi^{n}\left(p\left(x_{0}, x_{1}\right)\right)$ converges, we get that $\sum_{n=1}^{+\infty} p\left(x_{n}, x_{n+1}\right)$ converges too. It follows, for $m>n$,

$$
p\left(x_{m}, x_{n}\right) \leq \sum_{k=n}^{m-1} p\left(x_{k}, x_{k+1}\right) \leq \sum_{k=n}^{+\infty} p\left(x_{k}, x_{k+1}\right) \rightarrow 0, \quad \text { as } n \rightarrow+\infty .
$$

Now, from (4.1), we deduce that $\lim _{n, m \rightarrow+\infty} p\left(x_{n}, x_{m}\right)=0$ and hence $\left\{x_{n}\right\}$ is a 0 -Cauchy sequence in $X$. Since $X$ is a 0 -complete space, there exists $z \in X$ such that $x_{n} \rightarrow z$ and $p(z, z)=0$. For $x_{n} \in T x_{n-1}$ there is $y_{n} \in T z$ such that $p\left(x_{n}, y_{n}\right) \leq \psi\left(p\left(x_{n-1}, z\right)\right)$. From

$$
\begin{aligned}
p(z, T z) & \leq p\left(z, y_{n}\right) \leq p\left(z, x_{n}\right)+p\left(x_{n}, y_{n}\right) \\
& \leq p\left(z, x_{n}\right)+\psi\left(p\left(x_{n-1}, z\right)\right) \\
& \leq p\left(z, x_{n}\right)+p\left(x_{n-1}, z\right)
\end{aligned}
$$

as $n \rightarrow+\infty$, we obtain that $p(z, T z) \leq 0$; since $T z$ is closed, we have $z \in T z$. 
Example 2 Let $X=\mathbb{Q} \cap\left[0,+\infty\left[\right.\right.$ and $p: X \times X \rightarrow \mathbb{R}$ be defined by $p(x, y)=\frac{1}{4}|x-y|+$ $\frac{1}{2} \max \{x, y\}$. Then $(X, p)$ is a 0 -complete partial metric space. Let $T: X \rightarrow C(X)$ be defined by

$$
T x=\mathbb{Q} \cap\left[\frac{x}{4}, \frac{x}{2}\right] .
$$

Note that $T x$ is closed and bounded for all $x \in X$ under the given partial metric $p$.

We show that $T$ is a $\psi$-contractive mapping with respect to $\psi:[0,+\infty[\rightarrow[0,+\infty[$ defined by $\psi(t)=t / 2$ for all $t \in\left[0,+\infty\right.$ [. In fact, for all $x_{1}, x_{2} \in X$ and $y_{1} \in T x_{1}$, if $y_{1}=k x_{1} / 2$, $k \in \mathbb{Q} \cap[1 / 2,1]$, then we choose $y_{2}=k x_{2} / 2$. It implies that

$$
p\left(y_{1}, y_{2}\right)=k\left[\frac{1}{8}\left|x_{1}-x_{2}\right|+\frac{1}{4}\left|x_{1}-x_{2}\right|\right]=k \psi\left(p\left(x_{1}, x_{2}\right)\right) \leq \psi\left(p\left(x_{1}, x_{2}\right)\right) .
$$

By Theorem 3, $T$ has a fixed point $z=0$.

\section{Competing interests}

The authors declare that they have no competing interests.

\section{Authors' contributions}

All authors contributed equally and significantly in writing this paper. All authors read and approved the final manuscript.

\section{Author details}

${ }^{1}$ Dipartimento di Matematica e Informatica, Università di Palermo, Via Archirafi, 34, Palermo, 90123, Italy. ${ }^{2}$ Mathematical Institute of Serbian Academy of Sciences and Arts, Kneza Mihaila 36, Belgrade, 11000, Serbia. ${ }^{3}$ Faculty of Mechanical Engineering, University of Belgrade, Kraljice Marije 16, Beograd, 11120, Serbia.

\section{Acknowledgements}

The authors thank the referees for their valuable comments that helped us to improve the text. The first and fourth authors are supported by Università degli Studi di Palermo (Local University Project ex 60\%). The second and third authors are thankful to the Ministry of Science and Technological Development of Serbia (project III44006).

Received: 20 February 2012 Accepted: 20 August 2012 Published: 4 September 2012

\section{References}

1. Matthews, SG: Partial metric topology. In: Proc. 8th Summer Conference on General Topology and Applications. Ann. New York Acad. Sci. 728, pp. 183-197 (1994)

2. O'Neill, SJ: Partial metrics, valuations and domain theory. In: Proc. 11th Summer Conference on General Topology and Applications. Ann. New York Acad. Sci. 806, pp. 304-315 (1996)

3. Bukatin, MA, Scott, JS: Towards computing distances between programs via Scott domains. In: Adian S, Nerode, A (eds.) Logical Foundations of Computer Science. Lecture Notes in Computer Science, vol. 1234, pp. 33-43. Springer, Berlin (1997)

4. Bukatin, MA, Shorina, SY: Partial metrics and co-continuous valuations. In: Nivat, M (ed.), Foundations of Software Science and Computation Structures. Lecture Notes in Computer Science, vol. 1378, pp. 33-43. Springer, Berlin (1998)

5. Romaguera, S: Fixed point theorems for generalized contractions on partial metric spaces. Topol. Appl. 159, 194-199 (2012)

6. Ilić, D, Pavlović, V, Rakočević, V: Some new extensions of Banach's contraction principle to partial metric space. Appl. Math. Lett. 24, 1326-1330 (2011)

7. Abdeljawad, T: Fixed points for generalized weakly contractive mappings in partial metric spaces. Math. Comput. Model. 54, 2923-2927 (2011)

8. Abdeljawad, T, Karapinar, E, Tas, K: A generalized contraction principle with control functions on partial metric spaces. Comput. Math. Appl. (2011). doi:101016/j.camwa.2011.11.035

9. Abdeljawad, T, Karapinar, E, Tas, K: Existence and uniqueness of a common fixed point on partial metric spaces. Appl. Math. Lett. 24, 1900-1904 (2011)

10. Altun, I, Sola, F, Simsek, H: Generalized contractions on partial metric spaces. Topol. Appl. 157, 2778-2785 (2010)

11. Altun, I, Sadarangani, K: Corrigendum to "Generalized contractions on partial metric spaces" [Topol. Appl., 157 (2010), 2778-2785]. Topol. Appl. 158, 1738-1740 (2011)

12. Altun, I, Erduran, A: Fixed point theorems for monotone mappings on partial metric spaces. Fixed Point Theory Appl. 2011, Article ID 508730 (2011). doi:10.1155/2011/508730

13. Aydi, H, Abbas, M, Vetro, C: Partial Hausdorff metric and Nadler's fixed point theorem on partial metric spaces. Topol. Appl. 159, 3234-3242 (2012) 
14. Ćirić, L, Samet, B, Aydi, H, Vetro, C: Common fixed points of generalized contractions on partial metric spaces and an applications. Appl. Math. Comput. 218, 2398-2406 (2011)

15. Di Bari, C, Vetro, P: Fixed points for weak $\varphi$-contractions on partial metric spaces. Int. J. Eng. Contemp. Math. Sci. 1 , 5-13 (2011)

16. Đukić, D, Kadelburg, Z, Radenović, S: Fixed points of Geraghty-type mappings in various generalized metric spaces. Abstr. Appl. Anal. 2011, Article ID 561245 (2011). doi:10.1155/2011/561245

17. Golubović, Z, Kadelburg, Z, Radenović, S: Coupled coincidence points of mappings in ordered partial metric spaces. Abstr. Appl. Anal. 2012, 192581 (2012)

18. Ilić, D, Pavlović, V, Rakočević, V: Extensions of Zamfirescu theorem to partial metric spaces. Math. Comput. Model. 55, 801-809 (2012)

19. Karapinar, E, Erhan, IM: Fixed point theorems for operators on partial metric spaces. Appl. Math. Lett. 24, 1894-1899 (2011)

20. Nashine, HK, Kadelburg, Z, Radenović, S: Common fixed point theorems for weakly isotone increasing mappings in ordered partial metric spaces. Math. Comput. Model. (2011). doi:10.1016/j.mcm.2011.12.019

21. Oltra, S, Valero, O: Banach's fixed point theorem for partial metric spaces. Rend. Istit. Mat. Univ. Trieste 36, 17-26 (2004)

22. Paesano, D, Vetro, P: Suzuki's type characterizations of completeness for partial metric spaces and fixed points for partially ordered metric spaces. Topol. Appl. 159, 911-920 (2012)

23. Romaguera, S: A Kirk type characterization of completeness for partial metric spaces. Fixed Point Theory Appl. 2010, Article ID 493298 (2010)

24. Romaguera, S, Schellekens, M: Partial metric monoids and semivaluation spaces. Topol. Appl. 153, $948-962$ (2005)

25. Samet, B, Rajović, M, Lazović, R, Stoiljković, R: Common fixed point results for nonlinear contractions in ordered partial metric spaces. Fixed Point Theory Appl. 2011, 71 (2011). doi:10.1186/1687-1812-2011-71

26. Valero, O: On Banach fixed point theorems for partial metric spaces. Appl. Gen. Topol. 6, 229-240 (2005)

27. Vetro, F, Radenović, S: Nonlinear $\psi$-quasi-contractions of Ćirić-type in partial metric spaces. Appl. Math. Comput. (2012). doi:10.1016/j.amc.2012.07.061

28. Abbas, $M_{1}$ Jungck, J: Common fixed point results for noncommuting mappings without continuity in cone metric spaces. J. Math. Anal. Appl. 341, 416-420 (2008)

29. Vetro, P: Common fixed points in cone metric spaces. Rend. Circ. Mat. Palermo 56, 464-468 (2007)

30. Nadler, SB Jr.: Multi-valued contraction mappings. Pac. J. Math. 30, 475-487 (1969)

\section{Submit your manuscript to a SpringerOpen ${ }^{\ominus}$ journal and benefit from:}

- Convenient online submission

- Rigorous peer review

- Immediate publication on acceptance

Open access: articles freely available online

- High visibility within the field

- Retaining the copyright to your article 